\title{
Association of the lle-442-Met substitution in NCAPG with birth weight in German Angus and German Simmental cattle (Brief Report)
}

\author{
Assoziationsanalyse der Ile-442-Met Substitution im NCAPG-Gen mit \\ Geburtsgewicht bei Deutsch Angus und Deutsch Fleckvieh (Brief Report)
}

Kristina Glenske' ${ }^{1}$, Horst Brandt ${ }^{1}$ and Georg Erhardt ${ }^{1}$

${ }^{1}$ Department of Animal Breeding and Genetics, Justus-Liebig-University of Giessen, Giessen, Germany

\section{Background}

The optimal birth weight (BW) of a calf is important and an indicator of the chance to survive and performing later in life (Maltecca et al. 2009). The search for the genetic background of BW in cattle on BTA6 is in the focus of many studies. One QTL at $1 \mathrm{cM}$ was described in an Angus $\times$ Brahman cross population (Kim et al. 2003). Three QTL for BW had been identified at BTA6 at $10 \mathrm{cM}, 35-49 \mathrm{cM}$ and 83-86 cM in a commercial line of Bos taurus (Kneeland et al. 2004). One of these was confirmed in a Jersey $\times$ Holstein cross population as a putative QTL at $41 \mathrm{cM}$ (Maltecca et al. 2009). In a Holstein $\times$ Charolais cross cattle population a highly significant QTL for BW was detected on BTA6 in the same region between BM1329 and DIK1054 (Gutierrez-GIL et al. 2009). In another study with Holstein $\times$ Charolais the QTL was confirmed and the SNP in this QTL with the strongest effect on BW was in non-SMC condensing I complex, subunit G (NCAPG 1326T/G) (Eberlein et al. 2009). This SNP induced a Ile-442-Met substitution in the amino acid sequence.

It was the aim of this study to validate this SNP by analysing the effect of the lle-442-Met substitution in NCAPG on birth weight in two important beef cattle breeds in Germany.

\section{Procedures}

Animals

507 offspring (German Angus $\mathrm{n}=322$, German Simmental $\mathrm{n}=185$ ) of six NCAPG (Ile-442Met) heterozygous sires (German Angus $n=3$, German Simmental $n=3$ ) kept at Rudlos Experimental Farm, Hesse, Germany were included in this study. The birth weight (BW) was normally distributed in both breeds. In German Angus calves the mean of the BW with $38.29 \mathrm{~kg} \pm 5.45 \mathrm{~kg}$ is less than in German Simmental with $42.28 \pm 5.95 \mathrm{~kg}$.

Genotyping the single nucleotide polymorphism

The nonsynonymous SNP in NCAPG, 1326T>G with the amino acid substitution lle-442-Met, was genotyped by PCR-RFLP with Tasl as described in Eberlein et al. (2009). 


\section{Statistical analyses}

Association analyses between genotype and birth weight was done using a variance analysis including sire nested within breed, sex and genotype as fixed effects and dam and residual as random effects. The interaction of genotype and breed was also tested.

\section{Results and discussion}

The allele frequencies are significantly $(P<0.0001)$ different between the two breeds. In German Angus (GA) NCAPG, 1326T with $60.1 \%$ is the main allele while in German Simmental (GS) NCAPG, 1326G shows a high frequency with $67.0 \%$.

The effect of the interaction genotype*breed on BW was not significant, so the effect of the genotypes is the same in both breeds.

The genotype of NCAPG (Ile-442-Met) influenced the BW highly significant $(P<0.0001)$. The LSMeans for the genotypes are shown in Table 1.

Table 1

LSMeans and standard errors of the birth weight for the three NCAPG (Ile-442-Met)-genotypes

\begin{tabular}{lcc}
\hline genotype & LSMean of BW & standard error \\
\hline GG & $41.7^{\mathrm{a}}$ & 0.49 \\
GT & $40.7^{\mathrm{a}}$ & 0.36 \\
TT & $38.7^{\mathrm{b}}$ & 0.51 \\
\hline
\end{tabular}

a,bLSMeans with different letters differed significantly $(P=0.001)$

NCAPG G benefits the BW. Animals with the allele $\mathrm{G}$ (homozygous or heterozygous) showed a significant higher BW (Table 1). These results confirmed the study of Eberlein et al. (2009) with likewise higher BW in crossbreeds in combination with allele $\mathrm{G}$. They estimated the effect of the QTL-allele $(\mathrm{Q} / \mathrm{q})$ with $3.78 \mathrm{~kg}$ increase of BW with $\mathrm{Q}$ (associated with allele $\mathrm{G}$ of NCAPG Ile-442-Met). This is nearly the same effect like in our study. The LSMeans of both homozygous genotypes differed about $3 \mathrm{~kg}$ (Table 1). In GS allele $\mathrm{G}$ is the main allele and the BW in GS is about $4 \mathrm{~kg}$ higher than in GA.

Although the physiological role of NCAPG is still unknown, it is supposed, that the gene is involved in the arginine metabolism and therefore the muscle metabolism (Weikard et al. 2010). We could confirm the significant role of the NCAPG, 1326T>G SNP on birth weight in the two phenotypic different beef cattle breeds German Angus and German Simmental. Before implementation of this SNP in marker assisted selection further investigations for the optimal birth weight should be done. A higher BW can cause more difficult births or cesarean sections while a lower BW can be associated with reduced survival rate and daily gain during suckling period and therefore economical losses. With the further knowledge of the optimal BW and the frequency of the SNP in different breeds a decision for its use in breeding programms is possible. 


\section{References}

Eberlein A, Takasuga A, Setoguchi K, Pfuhl R, Flisikowski K, Fries R, Klopp N, Furbass R, Weikard R, Kühn C (2009) Dissection of genetic factors modulating fetal growth in cattle indicates a substantial role of the non-SMC condensin I complex, subunit G (NCAPG) gene. Genetics 183, 951-964

Gutierrez-Gil B, Williams JL, Homer D, Burton D, Haley CS, Wiener P (2009) Search for quantitative trait loci affecting growth and carcass traits in a cross population of beef and dairy cattle. J Anim Sci 87, 24-36

Kim JJ, Farnir F, Savell J, Taylor JF (2003) Detection of quantitative trait loci for growth and beef carcass fatness traits in a cross between Bos Taurus (Angus) and Bos Indicus (Brahman) cattle. J Anim Sci 81, 1933-1942

Kneeland J, Li C, Basarab J, Snelling WM, Benkel B, Murdoch B, Hansen C, Moore SS (2004) Identification and fine mapping of quantitative trait loci for growth traits on bovine chromosomes 2, 6, 14, 19, 21, and 23 within one commercial line of Bos Taurus. J Anim Sci 82, 3405-3414

Maltecca C, Weigel KA, Khatib H, Cowan M, Bagnato A (2009) Whole-genome scan for quantitative trait loci associated with birth weight, gestation length and passive immune transfer in a Holstein $\times$ Jersey crossbred population. Anim Genet 40, 27-34

Weikard R, Altmaier E, Suhre K, Weinberger KM, Hammon HM, Albrecht E, Setoguchi K, Takasuga A, Kühn C (2010) Metabolomic profiles indicate distinct physiological pathways affected by two loci with major divergent effect on Bos Taurus growth and lipid deposition. Physiol Genomics 42a, 79-88

Received 26 November 2010, accepted 22 December 2010.

Corresponding author:

Georg Erhardt

email: georg.erhardt@agrar.uni-giessen.de

Department of Animal Breeding and Genetics, Justus-Liebig-University of Giessen, Ludwigstr. 21 B, 35390 Giessen, Germany 